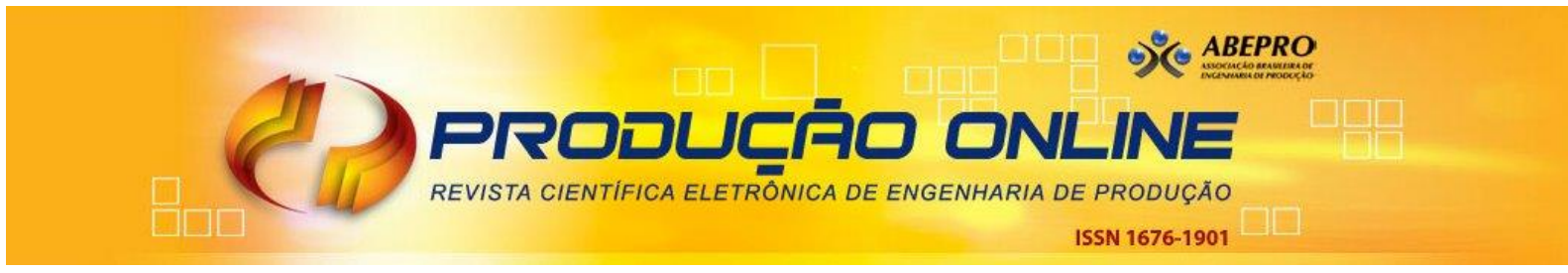

\title{
SISTEMAS DE LOGÍSTICA REVERSA DE PNEUS, PILHAS E BATERIAS IMPLANTADOS NO BRASIL: UMA ANÁLISE COMPARATIVA
}

\section{REVERSE LOGISTICS SYSTEMS OF TIRES AND BATTERIES IMPLEMENTED IN BRAZIL: A COMPARATIVE ANALYSIS}

\author{
Isadora Sanches Goeldner* E-mail: isadorasgoeldner@gmail.com \\ Barbara Tokarz* E-mail: barbaratokarz@icloud.com \\ Jade Ambrozi* E-mail: jade.sm.ambrozi@gmail.com \\ Pedro Henrique Rebellato* E-mail: pedro.rebelatto@hotmail.com \\ Alexandre Borges Fagundes* E-mail: alexandre.fagundes@udesc.br \\ Delcio Pereira* E-mail: delcio.pereira@udesc.br \\ Fernanda Hänsch Beuren* E-mail: fernanda.beuren@udesc.br \\ *Universidade do Estado de Santa Catarina (UDESC), Florianópolis, SC
}

\begin{abstract}
Resumo: Levando em consideração a problemática dos resíduos sólidos, o Conselho Nacional do Meio Ambiente buscou regulamentar medidas para o manejo e destinação corretos de resíduos que apresentassem risco socioambiental, tais como pilhas, baterias portáteis e pneus inservíveis. Nesse contexto, a logística reversa surge como importante ferramenta para o cumprimento da legislação e consequente redução de impactos ambientais adversos. Para o pleno atendimento a essas demandas, cabem análises acerca dos Sistemas de Logística Reversa quanto às suas práticas, vislumbrando possíveis melhorias. Nesse sentido, este artigo teve como principal objetivo, por meio de pesquisa bibliográfica e levantamento de dados, promover uma comparação entre os Sistemas de Logística Reversa de pilhas, baterias e pneus, pontuando seis tópicos de interesse: Fluxo reverso, Objetivos e metas, Gestão dos Sistemas, Número de postos de coleta, Contrapartida das empresas participantes e Quantidades de resíduos retornadas. Como resultado, inferiram-se pontos negativos e positivos, no tocante às metas e à gestão dos Sistemas pesquisados, trazendo contribuições à área da logística reversa, ressaltando assim a relevância da pesquisa para a elaboração de melhorias no funcionamento dos sistemas.
\end{abstract}

Palavras-chave: Logística Reversa. Acordos Setoriais. Pneus. Pilhas e Baterias. Política Nacional de Resíduos Sólidos.

\begin{abstract}
Considering the problem of solid waste, the National Environment Council sought to regulate the correct management and disposal of waste that presents a socio-environmental risks, such as batteries, portable batteries and unserviceable tires. In this context, reverse logistics emerges as an important tool for compliance with legislation and consequent reduction of adverse environmental impacts. In order to fully meet these demands, analyses of Reverse Logistics Systems are required regarding their practices, foreseeing possible improvements. In his sense, this article had as main objective, by means of bibliographic research and data survey, to promote a comparison between the Reverse Logistics Systems of batteries and tires, scoring six topics of interest: Reverse flow, Objectives and goals, Systems Management, Number of collection stations, Counterpart of the participating companies and Quantities of waste returned. As a result, negative and positive points were inferred regarding the goals and management of the researched Systems, bringing contributions to the area of reverse logistics, thus emphasizing the relevance of the research for the elaboration of improvements in the functioning of the systems.
\end{abstract}

Keywords: Reverse Logistic. Sectoral Agreements. Tires. Batteries. National Solid Waste Policy. 


\section{INTRODUÇÃO}

De acordo com a Associação Brasileira de Normas Técnicas (ABNT, 2004), resíduo sólido é toda substância em estado sólido ou semissólido, proveniente de atividades domésticas, comerciais ou industriais, e que não tem mais serventia.

O descarte inadequado de resíduos traz consequências negativas para a saúde pública e o meio ambiente, afetando, também, o quadro socioeconômico de muitas famílias. Organizações governamentais muitas vezes ignoram possibilidades de estabelecer parcerias com entidades envolvidas na busca por alternativas ambientalmente favoráveis, raramente utilizando-se das vantagens da cooperação (MMA, 2018).

Tendo em vista essa problemática, o Conselho Nacional do Meio Ambiente (CONAMA), buscou formas para regulamentar o destino ambientalmente adequado de materiais possivelmente danosos ao meio ambiente, como pilhas, baterias - por meio da Resolução ํo 401/08 - e pneus inservíveis - com a Resolução ํo 416/09.

Em vista do aumento da utilização de pilhas e baterias portáteis, surgiu a necessidade de reduzir, ao máximo possível, a geração de resíduos, como fração de um sistema integrado de Produção Mais Limpa, incentivando o desenvolvimento de novas técnicas e processos produtivos menos destrutivos ao meio ambiente, no âmbito produtivo nacional e também no controle de importação. Também se fazem necessárias as ações de conscientização dos consumidores sobre os riscos à saúde que as substâncias componentes das pilhas e baterias representam, além de conduzir estudos para substituir as substâncias perigosas ou reduzir seu teor ao máximo factível (CONAMA, 2008).

O pneu é um resíduo de classe II, que, diferentemente das pilhas e baterias, não é considerado tóxico. Porém, torna-se um transtorno ambiental pelo descarte incorreto, principalmente pelo seu acúmulo de água, que pode gerar doenças e contribuir para a proliferação do mosquito da dengue. Impactos ambientais maiores são observados em caso de queima a céu aberto destes pneus (RECICLANIP, 2008).

Apesar dos impactos ambientais causados pela destinação inadequada dos resíduos apresentados, o Brasil tem evoluído na redução da geração de resíduos 
sólidos urbanos (RSU), os números relativos a essa geração em 2016 tiveram uma queda de $2 \%$ comparados ao ano anterior, gerando um montante de 78,3 milhões de resíduos sólidos. Porém, a redução da geração e o aumento da cobertura de coleta foram os únicos índices que tiveram avanço, houve queda na disposição final dos RSU coletados, nos recursos aplicados pelos municípios e até mesmo na geração de empregos (ABRELPE, 2016).

Assim o artigo tem como objetivo apontar a disposição atual dos sistemas de logística reversa de pilhas, baterias e pneus inservíveis e então realizar uma análise comparativa das características de cada sistema, com a intenção de auxiliar o desenvolvimento de melhorias nos sistemas baseado nos resultados de comparação.

Para tal fim foi realizada uma pesquisa bibliográfica e levantamento de dados, além da comparação entre os referidos Sistemas de Logística Reversa, pontuando seis tópicos de interesse: fluxo reverso, objetivos e metas, gestão do Sistema, número de postos de coleta, contrapartida das empresas e quantidades a serem retornadas por meio da Logística Reversa.

\section{POLÍTICA NACIONAL DE RESÍDUOS SÓLIDOS E LOGÍSTICA REVERSA}

Foi sancionada em agosto e regulamentada em dezembro de 2010 a lei no 12.305 que instituiu Política Nacional de Resíduos Sólidos (PNRS), que reúne o conjunto de procedimentos e práticas a serem empregadas com base na gestão integrada e ao gerenciamento correto dos resíduos sólidos. Presume redução e prevenção à geração de resíduos; incentiva a prática de costumes de consumo sustentável e apresenta uma reunião de recursos para proporcionar o aumento da reciclagem e da reutilização dos resíduos sólidos e a destinação ambientalmente adequada dos rejeitos (BRASIL, 2010).

A PNRS estabelece a responsabilidade compartilhada dos produtores de resíduos: dos fabricantes, importadores, distribuidores, comerciantes, o cidadão e titulares de serviços de manuseio dos resíduos sólidos urbanos na Logística Reversa dos resíduos e embalagens (BRASIL, 2010). 
Um dos instrumentos para aplicação da responsabilidade compartilhada pelo ciclo de vida dos produtos é a Logística Reversa. É definida na alínea XII do Art. oㅡ da Lei que institui a PNRS como um:

\begin{abstract}
Instrumento de desenvolvimento econômico e social caracterizado por um conjunto de ações, procedimentos e meios destinados a viabilizar a coleta e a restituição dos resíduos sólidos ao setor empresarial, para reaproveitamento, em seu ciclo ou em outros ciclos produtivos, ou outra destinação final ambientalmente adequada (BRASIL, 2010).
\end{abstract}

Leite (2002) estabelece a Logística Reversa como uma área da logística empresarial destinada ao planejamento e controle de fluxo e informações referentes a bens empresariais, no que tange seu tratamento pós-venda e pós-consumo, bem como seu retorno ao ciclo produtivo, "agregando-Ihes valor de diversas naturezas: econômico, ecológico, legal, logístico, de imagem corporativa, entre outros".

\title{
3 OS SISTEMAS DE LOGÍSTICA REVERSA DE PILHAS E BATERIAS E PNEUS
}

Neste tópico são abordados os Sistemas de Logística Reversa de Pilhas e Baterias Portáteis e Pneus Inservíveis, evidenciando seis pontos de interesse: fluxo reverso, objetivos e metas, gestão do Sistema, número de postos de coleta, contrapartida das empresas e quantidades a serem retornadas por meio da Logística Reversa.

\subsection{Legislação pertinente às Pilhas e Baterias}

Em vista da disseminação e vasta utilização de pilhas e baterias portáteis em todo o território nacional, considera-se de vital importância informar os consumidores sobre os riscos à saúde que os contaminantes das pilhas e baterias representam (CONAMA, 2008).

Em 1999, foi publicada a Resolução CONAMA no 257, que instituía os limites máximos de cádmio, chumbo e mercúrio para pilhas e baterias comercializadas em território nacional (CONAMA, 1999a). Em novembro de 2008 foi publicada a resolução no 401/08, revogando a primeira, e também instituindo valores máximos 
de metais pesados a estarem presentes nas pilhas e baterias, assim como padrões para seu gerenciamento ambientalmente adequado (CONAMA, 2008).

Atualmente trabalha-se com as seguintes legislações, pertinentes à logística reversa de pilhas e baterias:

- Resolução CONAMA nำ 401/2008;

- Lei no 12.305, que institui a Política Nacional dos Resíduos Sólidos;

- Resolução ANTT no 420/2004, estabelece requisitos regulatórios para o transporte terrestre de produtos perigosos;

Além de portarias e Normas Brasileiras (NBR) relativas ao transporte de materiais perigosos.

\subsubsection{O Fluxo Reverso para Pilhas e Baterias}

A produção anual no Brasil, no ano de 2008 era de cerca de 800 milhões de pilhas alcalinas e outras 10 milhões de baterias para telefones móveis; além disso, deve-se contabilizar os produtos importados, quer sejam oriundos de fontes legais ou não. Juntos, produção nacional e importações somam 1,2 bilhões de pilhas alcalinas e 400 milhões de baterias para telefones móveis (ABINEE, 2008).

De acordo com a Resolução CONAMA 401/2008, os consumidores de pilhas e baterias portáteis devem levá-las até um ponto de coleta do Sistema (CONAMA, 2008). As pilhas e baterias devem, em sua totalidade, ser encaminhadas para destinação final ambientalmente adequada, por responsabilidade do fabricante ou importador (CONAMA, 2008).

A inciativa de Logística Reversa de Pilhas e Baterias mais significativa atuante no país hoje é o Programa ABINEE Recebe Pilhas. De maneira a facilitar e unificar o processo, as empresas associadas ao programa decidiram pela sua terceirização. Assim, cada fabricante e distribuidor assinou, individualmente, contrato com uma empresa especializada em logística reversa, a GM\&Clog, e uma recicladora, a Suzaquim, após realização de auditoria pelos fabricantes interessados (FARIA; MENDES; RUIZ, 2015).

Quando os postos de coleta atingem um volume mínimo de $30 \mathrm{~kg}$ de material, entram em contato com a GM\&C (ABINEE, 2017a), que realiza a "coleta, triagem 
das peças por marca, a armazenagem temporária em embalagens adequadas e consolidação de carga para destinação final ambientalmente correta junto ao reciclador" (MENDES; RUIZ; FARIA, 2015).

A empresa Suzaquim recebe a massa total de objetos da GM\&C e realiza o reprocessamento de pilhas e baterias, sem a geração de rejeitos, de maneira a destiná-las adequadamente (MENDES; RUIZ; FARIA, 2015).

O primeiro passo do reprocessamento é a remoção das capas das pilhas, de maneira a permitir o tratamento das substâncias em seu interior; em seguida, os materiais passam por um processo químico - onde óxidos metálicos são recuperados para serem utilizados como corantes, ou um processo térmico, onde é possível a recuperação do zinco para utilização na indústria (ABINEE, 2017).

Após o reprocessamento dos objetos, a recicladora emite um certificado que comprova o reprocessamento e a destinação final ambientalmente adequada das pilhas e baterias recebidas, contendo o volume tratado para cada fabricante e importador, de maneira a repartir proporcionalmente os gastos com o processo, e facilitar a prestação de contas frente ao órgão ambiental competente (MENDES; RUIZ; FARIA, 2015).

Todo fabricante e importador deve apresentar ao IBAMA plano de gerenciamento de pilhas e baterias, contemplando o processo reverso do produto, bem como laudo físico-químico de composição, além de Relatório Anual de Atividades, envolvendo especificações sobre a produção/importação, bem como informações sobre a coleta, transporte e destinação final do objeto (CONAMA, 2008; DOU, 2012).

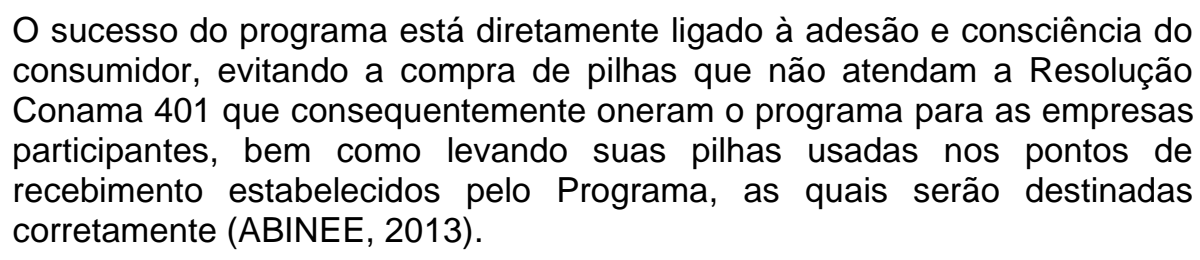

A Figura 1 apresenta um fluxograma contendo o fluxo reverso para pilhas e baterias. 
Figura 1 - Fluxo reverso para pilhas e baterias

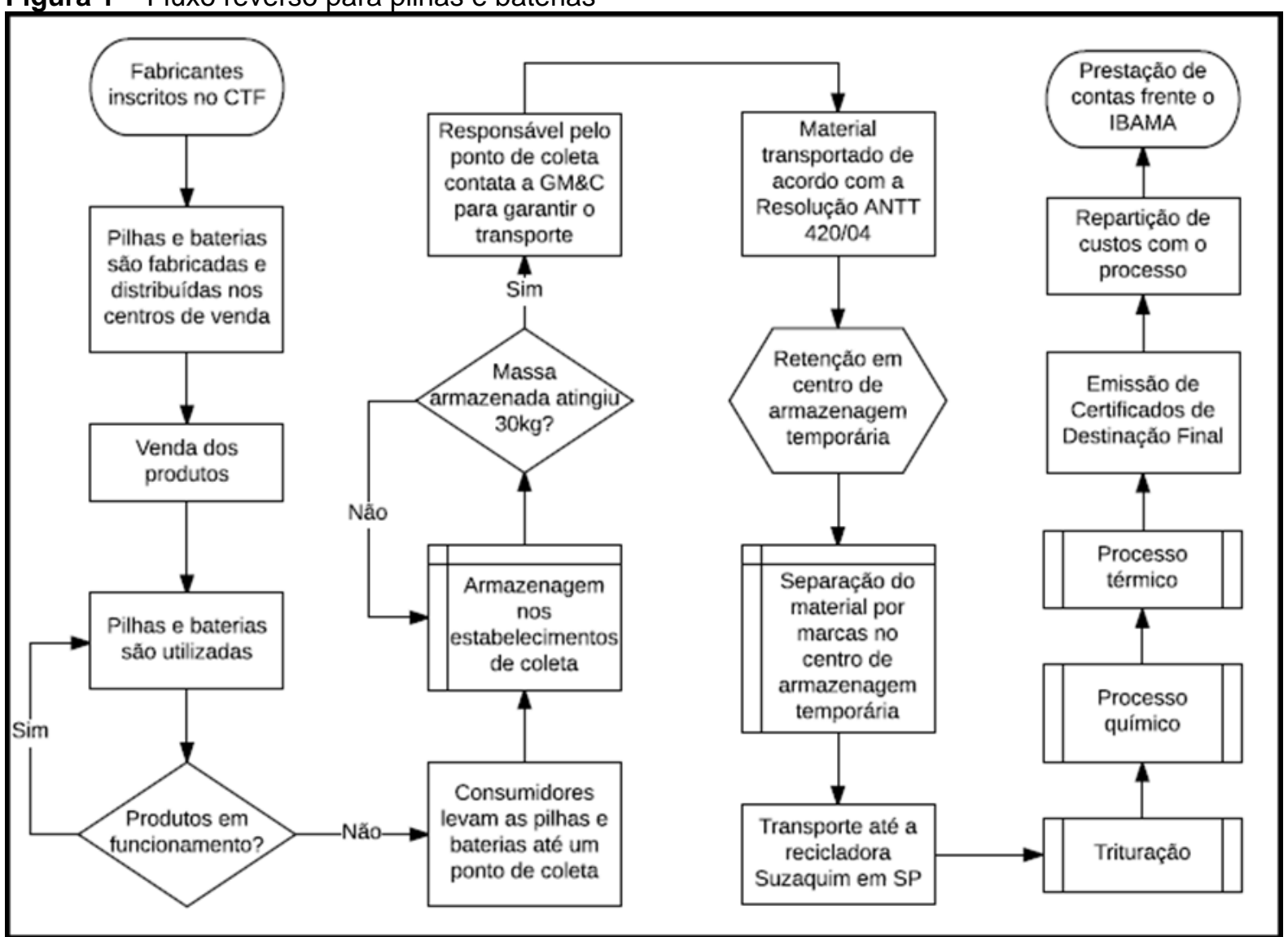

Fonte: Fagundes et al. (2017).

\subsubsection{Objetivos e Metas estabelecidas}

O Decreto no 7404/2010, em seu Art. 15으, determina que os sistemas de logística reversa deverão ser estabelecidos por meio de acordos setoriais, regulamentos expedidos pelo poder público ou termos de compromisso (BRASIL, 2010a). Tendo em vista a não existência de alguma das opções acima referentes à logística reversa de pilhas e baterias, o sistema continua sendo gerido pela Resolução CONAMA 401/2008.

Alguns estados brasileiros apresentam termos de compromisso, assinados por associações de comerciantes e o governo do estado, tendo a ABINEE e órgãos estaduais responsáveis por fiscalização ambiental como anuentes. Os termos têm o objetivo de incentivar o cumprimento da Resolução Conama no 401/08, no que se refere às obrigações de consumidores e comerciantes, definindo metas e delimitando o funcionamento do Sistema para aquele estado (FECOMÉRCIO/SP, 2017; SEMA, 2017). 
Tal resolução, considerando a necessidade de minimizar impactos negativos causados pelo descarte incorreto de pilhas e baterias, especialmente aquelas contendo chumbo, cádmio e mercúrio em seus compostos; visando reduzir o máximo possível a geração de resíduos, procurando integrar um Sistema de Produção mais Limpa; e estimulando a elaboração de processos limpos de tratamento de pilhas e baterias no Brasil, estabelece valores máximos de cádmio, chumbo, mercúrio e seus compostos a estarem presentes nas pilhas e baterias portáteis fabricadas ou importadas no Brasil (CONAMA, 2008; BRASIL, 2010).

\subsubsection{Gestão do Sistema de Logítica Reversa}

Após a publicação da Resolução CONAMA nº 257/99, observou-se iniciativas das empresas em relação a processos de logística reversa de pilhas e baterias, principalmente quando pressionadas por ONGs e algumas prefeituras (MENDES; RUIZ; FARIA, 2015); mas foi só após a publicação da Resolução nº 401/2008 que houve uma integração nacional em relação à logística reversa. Essa integração se deu por meio do Programa ABINEE Recebe Pilhas (PARP), instituído a partir de uma ação conjunta de fabricantes e importadores de pilhas e baterias, atuantes em território nacional (MENDES; RUIZ; FARIA, 2015; GM\&C, 2017).

O Programa foi fundado em 2010 e abrange a Resolução CONAMA 401/2008, garantindo assim, a responsabilidade pela logística reversa das pilhas e baterias de fabricantes participantes, tais como Alfacell, ATTIC, Bic, Carrefour, Comexport, Cyber Energy, Duracell, Elgin, Energizer, Eveready, Goal, SC Johnson, Kodak, Maxprint, Panasonic e Philips (ABINEE, 2013; GM\&C, 2017).

Além disso, as demais pilhas auferidas no mesmo lote recebem tratamento, no entanto diferenciado, de modo que as regulares serão notificadas pela Abinee referente à marca responsável a fim de que avoquem seu passivo, enquanto as ilegais serão comunicadas às autoridades de órgãos, tais como Polícia Federal, Receita Federal, Ministério do Meio Ambiente e o próprio Ibama de maneira que adotem as medidas necessárias (ABINEE, 2013).

A partir de 2018, a GREEN Eletron, também gestora do sistema de logística reversa de equipamentos eletroeletrônicos e seus componentes, assume a gestão 
do sistema de pilhas e baterias (ABINEE, 2018).

\subsubsection{Números de Postos de Coleta}

Para o Sistema de Logística Reversa de pilhas e baterias, os pontos de coleta se dividem em primários e secundários. Os pontos primários são todos os comerciantes de pilhas e baterias, que, em cumprimento à Resolução Conama no 401/08, devem receber pilhas e baterias dos consumidores. Os pontos de coleta secundários são aqueles participantes do PARP, dispostos em uma lista disponibilizada pelo operador logístico GM\&Clog (FECOMERCIO/SP, 2017).

Atualmente o PARP conta com 1250 postos de coleta de pilhas e baterias espalhados pelo país (GM\&C, 2017). A Figura 2 mostra a distribuição dos postos de coleta, segundo dados do sítio eletrônico da GM\&C.

Figura 2 - Localização de Postos de Coleta

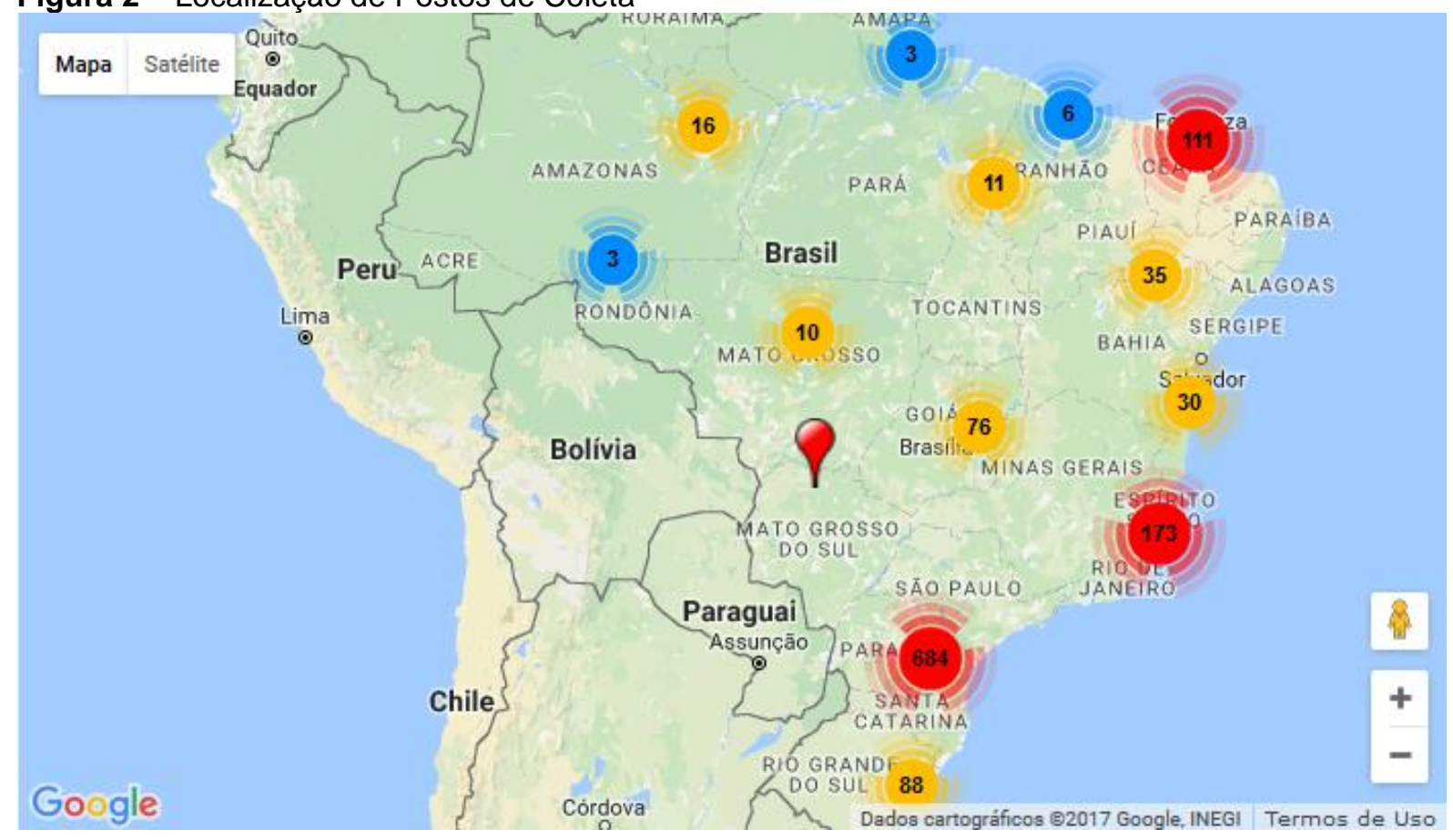

Fonte: GM\&C (2017)

A GM\&C recebe, também, pilhas de pontos diferentes dos estabelecidos no Sistema, desde que o ponto de coleta seja uma instituição de ensino, um órgão público ou uma ONG; esteja localizado em até $50 \mathrm{~km}$ de distância de uma capital; e o volume armazenado seja de no mínimo 30kg (ABINEE, 2017). 
Caso empresas privadas desejem utilizar o PARP como meio de destinação final para pilhas e baterias geradas em sua própria atividade, podem encaminhar o material a um ponto de coleta cadastrado no site - para quantidades inferiores a 10kg; ou arcar com o custo do transporte até o centro de consolidação do Programa, em São Paulo (ABINEE, 2017).

\subsubsection{Contrapartida das Empresas}

Os custos incorridos pelo sistema de Logística Reversa de pilhas e baterias portáteis gerados pelos serviços das empresas GM\&C e Suzaquim são integralmente absorvidos pelas empresas gestoras do PARP e são rateados de acordo com o balanço de massa realizado na etapa de triagem por fabricante (MENDES; RUIZ; FARIA, 2015).

Um ponto importante a ser ressaltado é a escassez de fiscalização da parte do Governo para com a comercialização de pilhas e baterias advindas do contrabando. O sistema acaba recolhendo pilhas de fabricantes que não contribuem para seu funcionamento e que, por vezes, possuem concentração de metais pesados muito acima do permitido por lei no Brasil, situação que acaba penalizando os associados ao PARP, devido à concorrência desleal (MENDES; RUIZ; FARIA, 2015).

3.1.6 Quantidades a serem retornadas por meio da Logística Reversa

A Resolução CONAMA 401/2008 não estabelece metas para coleta, deixando a cargo dos fabricantes e importadores de pilhas e baterias associados ao Programa ABINEE Recebe Pilhas a determinação da quantidade a ser retornada pelos mesmos.

Lyrio e Chaves (2015, p.224) descrevem tal feito, destacando também que a Resolução não apresenta evidências que motivem fabricantes e importadores a buscar maiores índices de retorno, fato que "dificulta a avaliação da eficácia no cumprimento da norma". 
Segundo os números disponibilizados no sítio eletrônico da GM\&C, até o momento já foram recolhidas mais de 11.470 toneladas de pilhas e baterias portáteis em todo o território nacional (GM\&C, 2017).

\subsection{Legislação Pertinente aos Pneus}

Considerando a necessidade de disciplinar a destinação de pneus inservíveis; já que podem resultar em sérios riscos à saúde pública e ao meio ambiente, além do que, se incorretamente dispostos, representam passivo ambiental; com o propósito de assegurar que estes pneumáticos sejam destinados corretamente o mais próximo possível do seu local de produção, o CONAMA criou a Resolução no 416, de 30 de Setembro de 2009 para regulamentar a destinação dos pneus inservíveis (CONAMA, 2009).

Define-se como pneu ou pneumático:

\footnotetext{
Componente de um sistema de rodagem, constituído de elastômeros, produtos têxteis, aço e outros materiais que quando montado em uma roda de veículo e contendo fluido (s) sobre pressão, transmite tração dada a sua aderência ao solo, sustenta elasticamente a carga do veículo e resiste à pressão provocada pela reação do solo (CONAMA, 2009).
}

A resolução em vigor propõe que para cada pneu novo comercializado, os fabricantes e importadores efetuem a destinação adequada de um pneu inservível (CONAMA, 2009).

A Resolução $n^{0}$ 258, art. $1^{\circ}$ do Conselho Nacional de Meio Ambiente CONAMA, determina que pneus inservíveis existentes no território nacional são considerados passivos ambientais, portanto, fabricantes e importadores de pneumáticos são obrigados a dar a correta destinação a estes pneus na proporção referente às quantidades fabricadas e/ou importadas, já esclarecidas na resolução pertinente CONAMA (1999).

\subsubsection{O Fluxo reverso para Pneus}

Quando um pneu chega ao final de sua vida útil, este deve ser deixado em um Ecoponto, um posto de coleta disponibilizado pelas prefeituras municipais. 
Assim, o consumidor, no ato da troca de pneu, deverá deixar o pneu inservível, que posteriormente será coletado pela Reciclanip e direcionado a uma correta destinação ambiental (FLORIANI, FURLANETTO, SEHNEM, 2016).

A Reciclanip é uma empresa de iniciativa privada dos associados da Associação Nacional da Indústria de Pneumáticos (ANIP), encarregada em transferir, dos Postos de Coletas, pneus para empresas de trituração, quando necessário, de onde os pneus serão encaminhados para destinação final (RECICLANIP, 2018).

No Brasil, uma das formas mais comuns de reaproveitamento dos pneus inservíveis é como combustível alternativo para as indústrias de cimento. Outros usos dos pneus são na fabricação de solados de sapatos, borrachas de vedação, dutos pluviais, pisos para quadras poliesportivas, pisos industriais, além de tapetes para automóveis. Mais recentemente, surgiram estudos para utilização dos pneus inservíveis como componentes para a fabricação de manta asfáltica e asfalto-borracha, processo que tem sido acompanhado e aprovado pela indústria de pneumáticos (RECICLANIP, 2018a)

A responsabilidade pela coleta cabe aos fabricantes e importadores, estes também são encarregados de dar destinação adequada aos pneus inservíveis existentes no território nacional, na proporção definida. A elaboração de diretrizes para a coleta dos pneus inservíveis existentes no país é dever dos revendedores, distribuidores, destinadores, consumidores e poder público (CONAMA, 2009).

Os fabricantes e os importadores de pneus novos, deverão implementar pontos de coletas de pneus usados, podendo envolver os pontos de comercialização de pneus, os municípios, borracheiros e outros (CONAMA, 2009).

A Figura 3 apresenta um fluxograma contendo o fluxo reverso dos pneus inservíveis. 
Figura 3 - Fluxo reverso para pneus inservíveis

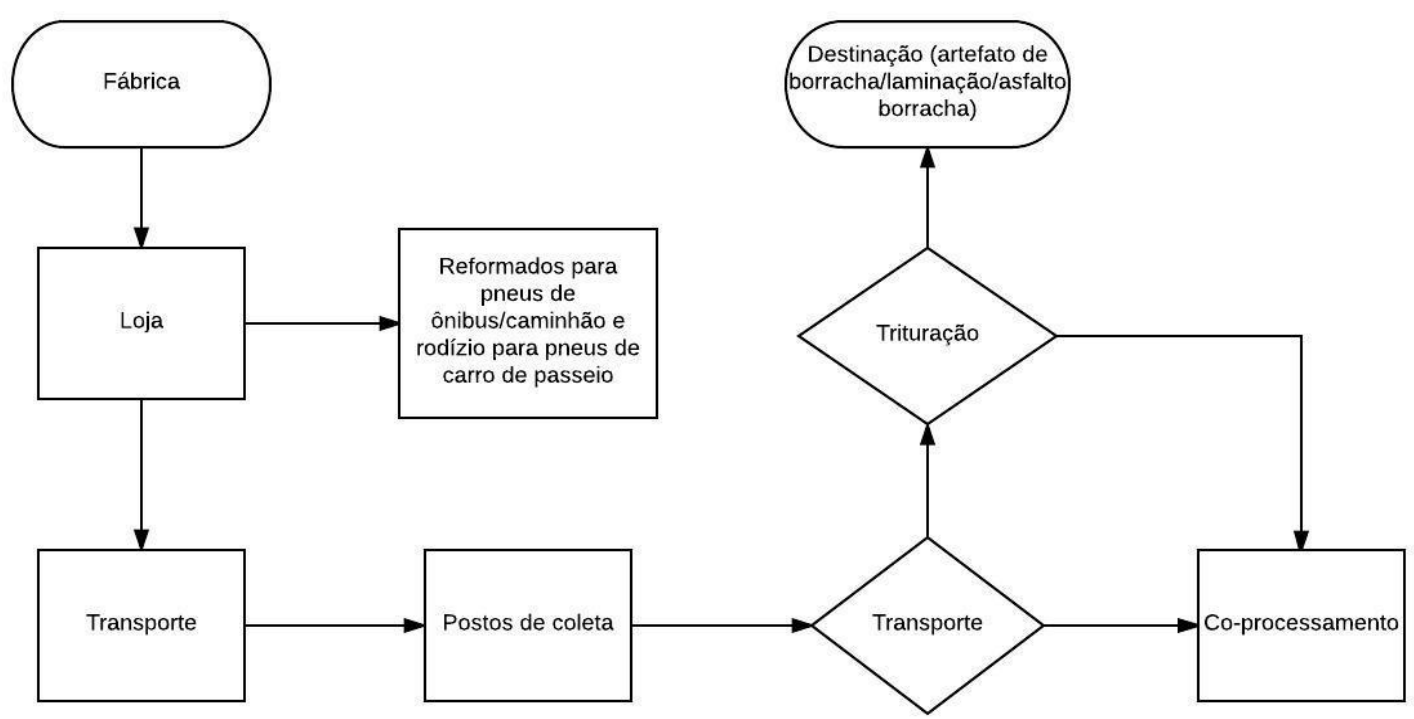

Fonte: Autoria própria, baseado em RECICLANIP (2018a)

\subsubsection{Objetivos e Metas estabelecidos}

A Missão da Reciclanip é gerir o processo de coleta de pneus inservíveis e a sua correta destinação em todas as regiões, visando assegurar a melhor destinação de pneus, com a participação de toda a cadeia produtiva e viabilizar a sua independência operacional e financeira (FLORIANI, FURLANETTO, SEHNEM, 2016).

Dentre as estratégias da Reciclanip estão "Estruturar a cadeia de coleta e destinação de pneus inservíveis com a participação da rede de revendedores e reformadores, poder público e sociedade, em todo o país"' (RECICLANIP, 2018b). Dar a destinação ambiental para os pneus disponíveis, contribuir para estudos e pesquisa sobre o ciclo de vida dos pneus e "Desenvolver, em conjunto com o poder público, programas e ações de conscientização ambiental para a população" (RECICLANIP, 2018b).

Para dispor de metas quantitativas os fabricantes/importadores devem fornecer à Reciclanip a meta de destinação de pneus inserviveis da empresa, através dos seguintes cálculos: 
Meta dos fabricantes (em peso, referente a um ano calendário) $=\{[$ (total de pneus produzidos + total de pneus importados) - (total de pneus exportados + total de pneus que equipam veículos novos) ] x 0,7\} (IBAMA, 2017)

Meta dos importadores $=[$ (Total de pneus nacionalizados - Total de pneus comercializados) $\times 0,7]$ (IBAMA, 2009)

Observação: o fator de multiplicação 0,7 refere-se ao desconto de $30 \%$ pelo desgaste do pneu novo, devido ao seu uso (IBAMA, 2017)

\subsubsection{Gestão do Sistema de Logística Reversa}

A ANIP é uma associação que representa os fabricantes de pneumáticos do Brasil há mais de 45 anos, Goodyear, Pirelli, Michelin, Bridgestone, Continental, Neotec, Maggion, Rinaldi, Sumitomo, Levorin e Titan fazem parte destas fabricantes. As indústrias de pneumáticos valem-se de instrumentos implantados pela ANIP, que criou o "Programa Nacional de Coleta e Destinação de Pneus Inservíveis", que conta hoje com a participação de mais de 834 municípios conveniados. Nesse sentido, definida pela Resolução 416/2009 do CONAMA, estas empresas se uniram para atuar na coleta e destinação de pneus inservíveis, procedimento que acarreta no atendimento da finalidade ambiental (BATISTA; MONTEIRO; SAMPAIO, 2015).

\footnotetext{
Devido à abrangência nacional assumida pelo programa, bem como ao seu pioneirismo e grau de profissionalização, tornou-se necessária à constituição de uma entidade exclusivamente dedicada à gestão e aprimoramento dos trabalhos sobre o pós-consumo dos pneumáticos (RECICLANIP, 2008).
}

$\mathrm{Na}$ sequência foi criada a Reciclanip, uma gestora sem fins lucrativos que proporciona a destinação ambientalmente adequada de pneus inservíveis por todo o país (RECICLANIP, 2008).

A implantação da Reciclanip segue o padrão das empresas europeias, que possuem larga experiência na destinação ambientalmente adequada de pneus inservíveis. Porém, estas empresas europeias são remuneradas pelos serviços que prestam, já a RECICLANIP é projetada para que os fabricantes de pneus arquem com todos os custos (RECICLANIP, 2018c). 


\subsubsection{Números de Postos de Coleta}

Os pontos de coletas são disponibilizados pelas esferas municipais, onde munícipes, borracheiros e revendedores podem se tornar um ponto, até mesmo pneus recolhidos por programas de limpeza municipal são destinados pela Reciclanip (RECICLANIP, 2018d).

Este recolhimento é realizado através de transportes conveniados, que podem ser também terceirizados, porém, devem ser autorizados e licenciados pelos órgãos ambientais e estaduais. Devido à comunicação dos pontos de coleta com a Reciclanip, esta é contatada pelos pontos ou pela prefeitura, quando é atingido um número de 2000 pneus de passeio ou 300 pneus de caminhões, assim é feita a retirada dos pneus inservíveis (RECICLANIP, 2018d).

Realiza-se a expansão do número de Postos de Coleta de Pneus no País, devido a acordos feitos pelas Prefeituras Municipais. Isso é demonstrado no relatório anual de Pneumáticos, publicado pelo Ibama, o qual vem exibindo resultados positivos a cada ano. Até o final de 2016 eram 1723 pontos de coleta, sendo 932 pontos e municípios com população acima de 100 mil habitantes, restando apenas 13 municípios com esta população sem pontos de coleta (IBAMA, 2017).

\subsubsection{Contrapartida das Empresas}

Considerada uma das maiores iniciativas da indústria brasileira na área de responsabilidade pós-consumo, a Reciclanip faz o trabalho de coleta e destinação de pneus inservíveis que é comparável aos maiores programas de reciclagem desenvolvidos no país, como o de latas de alumínio e embalagens de defensivos agrícolas (RECICLANIP, 2017).

Ao longo dos anos, o Programa expandiu sua atuação em todas as regiões do país, o que levou os fabricantes a criar uma entidade voltada exclusivamente para a coleta e destinação de pneus no Brasil. Criada pelos fabricantes de pneus novos Bridgestone, Goodyear, Michelin e Pirelli e, em 2010, a Continental juntou-se à entidade, em 2014, a Dunlop tambem começou a fazer parte da RECICLANIP, para unificar o programa nacional de coleta e destinação de pneus inservíveis. As 
atividades atendem a resolução 416/09 do CONAMA, que regulamenta a coleta e destinação dos pneus inservíveis (RECICLANIP, 2017d).

\begin{abstract}
A criação da Reciclanip demonstra a responsabilidade da indústria de pneumáticos com as questões ambientais e com o estabelecimento de condições que permitam 0 desenvolvimento sustentável do País, valorizando, sobretudo, a preservação da natureza e a qualidade de vida e o bem-estar da população (RECICLANIP, 2017).
\end{abstract}

Atualmente os custos são de total responsabilidade dos fabricantes, o que encarece a parcela de pneus destinados à exportação pois não envolve os outros participantes da cadeia. Porém o objetivo é distribuir os custos da logística reversa por toda a cadeia, desde fabricantes a revendedores e consumidores.

\title{
3.2.6 Quantidades a serem retornadas por meio da Logística Reversa
}

O setor de pneus inserviveis chegou a coletar quatro milhões de toneladas desde o início do programa. De janeiro a outubro do ano de 2016, a Reciclanip coletou e destinou de forma ambientalmente correta mais de 383,9 mil toneladas do material, quantia que equivale a 76,8 milhões de unidades de pneus de carros de passeio (RECICLANIP, 2018f).

Desde 2010, ano do primeiro relatório do IBAMA, a Reciclanip vem ultrapassando sua meta logística. Por exemplo, em 2015, a Reciclanip superou a meta de logística reversa estabelecida pelo IBAMA chegando a $101,7 \%$ de recolhimento e destino correto de pneus (RECICLANIP, 2018f)

No último relatório pneumático apresentado pelo Ibama em 2017, verificou se que os fabricantes cumpriram 100,9\% da meta nacional, destinando 404.382,13 toneladas de pneus, enquanto os importadores cumpriram $83,64 \%$ da meta nacional, destinando 89.017,00 toneladas (IBAMA, 2017).

\section{METODOLOGIA DA PESQUISA}

Inicialmente foi executada uma revisão bibliográfica envolvendo a Logística Reversa dos objetos em estudo compreendendo a Política Nacional dos Resíduos Sólidos, esta pesquisa foi realizada através de estudos análogos acadêmicos, 
incluindo ainda, livros, periódicos e sites da internet, de maneira a gerar críticas e deduções finais sobre o tema.

Foram utilizadas metodologias técnicas bem como levantamento de dados e pesquisa bibliográfica; além disso, esta análise se caracteriza por ser de natureza aplicada, quantitativa e descritiva (GIL 2002; MENEZES; SILVA, 2005; LAKATOS; MARCONI, 2006).

\section{ANÁLISE E DISCUSSÃO}

Foram estabelecidos seis tópicos relevantes através dos referenciais teóricos encontrados para, neste instante, possibilitar uma comparação por meio dos mesmos critérios.

\subsection{Os Fluxos Reversos estabelecidos para os dois sistemas}

A nível macro, em ambos os Sistemas de Logística Reversa é responsabilidade do consumidor levar os objetos até um ponto de coleta estabelecido, que, por sua vez, ao atingir os montantes mínimos pré-definidos, os encaminha para destinação ambientalmente adequada.

As pilhas e baterias são direcionadas a um único local para reprocessamento, bem como os pneus. Após isso, ambos assumem um fluxo reverso mais difuso, abarcando diferentes possibilidades de aplicações.

Considerando as características dos produtos em questão, e as determinações que regem os Sistemas, pode-se inferir que a logística reversa de pneus tem como fator favorecedor a troca do usado pelo novo, no ato da aquisição do produto novo, nos locais de venda dos mesmos.

\subsection{Os Objetivos e Metas estabelecidas para os dois sistemas}

Ambos os objetivos referentes a pneus, pilhas e baterias tem como ponto principal alcançar a sua destinação correta, de maneira a minimizar os impactos negativos ambientais bem como o cumprimento das leis estabelecidas. 
Quanto às metas, o Sistema de Logística Reversa de pilhas e baterias não traz uma definição numérica clara a ser alcançada anualmente; já o de pneus traça metas anuais de acordo com fórmulas específicas, para fabricantes e importadores.

Porém, metas são necessárias para direcionar a empresa, orienta-la no caminho que deve ser seguido para atingir a sua missão como organização (BARBOSA; BRONDANI, 2005). Ao não trabalhar com metas, o Sistema de pilhas e baterias desvia-se da possibilidade de melhoria contínua; se o Sistema empregasse indicadores, poderia ter melhor controle de seu funcionamento, possibilitando a previsão de um comportamento futuro.

A meta de 1:1 estabelecida pelo Sistema de pneus - "para cada pneu novo comercializado para o mercado de reposição, as empresas fabricantes ou importadoras deverão dar destinação adequada a um pneu inservível" (IBAMA, 2016, p. 13) - é louvável, uma vez que se pretende dar destinação correta a 100\% dos produtos fabricados/importados.

Em contrapartida, o desgaste dos pneus durante o seu uso é estimado em $30 \%$ da massa total, caracterizando, assim, uma previsão de retorno (máxima) de $70 \%$ (em massa) dos produtos fabricados/importados.

Ainda com relação as metas alguns termos de compromisso assinados em âmbito estadual definem metas para os sistemas. Apesar da iniciativa dos termos de compromisso de pilhas em definir metas, as mesmas não se apresentam eficientes uma vez que representam apenas o objetivo do sistema, e não uma perspectiva de crescimento. Os termos de compromisso referentes ao sistema de pneus apresentavam as mesmas metas da Reciclanip, o que não acrescenta em melhorias ao sistema.

\subsection{A Gestão dos Sistemas de Logística Reversa}

No que diz respeito a gestão dos sistemas, a logística reversa de pneus é gerida por uma entidade sem fins lucrativos, resultado da consolidação do Programa Nacional de Coleta e Destinação de Pneus Inservíveis, enquanto a logística reversa de pilhas é gerida por uma associação (ABINEE), a qual tem outros objetivos e não 
foi criada apenas e especificamente para reger a logística reversa como é o caso da entidade de pneus.

Assim, a Reciclanip é responsável pela grande maioria das etapas da cadeia, concentra maiores informações e ações em apenas uma entidade, tornando mais fácil o entendimento do sistema para a sociedade.

Já a ABINEE é tida como um agente facilitador, pois terceiriza toda parte da logística reversa que é de responsabilidade dos fabricantes. Assim há uma dispersão maior de informações entre as empresas terceirizadas e a associação, e a falta de concentração de informações dificulta o entendimento e a popularização do programa.

\subsection{A Definição dos números de Postos de Coleta para os dois sistemas}

Em ambos os sistemas os fabricantes e importadores determinam onde serão estabelecidos postos de coleta, porém a distribuição dos pontos baseia-se em fatores diferentes.

O sistema de pneus possui uma distribuição territorial de pontos de coleta maior que o sistema de pilhas, em ambos há uma grande concentração de postos nas regiões sul e sudeste, porém o sistema de pilhas possui número de pontos insuficiente em alguns estados, como é o exemplo de Santa Catarina que possui apenas um ponto de coleta.

Essa má distribuição de pontos de coleta pode ser resultado da falta de termos de compromissos entre o poder estadual e as gestoras, e a até mesmo dos critérios de implantação de pontos.

Atualmente confere-se 1723 postos de coleta de pneus inservíveis estabelecidos em território nacional, e 1250 de pilhas e baterias portáteis.

\subsection{A Contrapartida das empresas}

Nos sistemas estudados, cabe aos fabricantes e importadores arcar com os custos do processo de logística reversa, desde o transporte até a destinação final ambientalmente adequada. Porém, na cadeia de pneus, a Reciclanip é responsável 
pelo sistema desde o transporte de pneus dos pontos de coleta primário, até o transporte dos mesmos à recicladora, enquanto a GM\&C, empresa terceirizada do sistema de pilhas, é responsável somente a partir do ponto de coleta secundário.

Deste modo o custo para os fabricantes de pneus é maior, pois os fabricantes de pneus novos arcam com os custos de toda a cadeia, diferentemente dos fabricantes de pilhas que custeiam apenas a partir de pontos secundários. Esse alto custo mal distribuído pela cadeia reversa de pneus pode encarecer o produto, inclusive a fração de pneus destinados a exportação.

Ademais, ambos os fabricantes e importadores de pneus e pilhas e baterias tem a responsabilidade de declarar, em relatório anual de atividades, a quantidade de material produzido/importado, bem como sua classificação por modelo, peso e local para onde foi enviado. No caso de pilhas e baterias, os fabricantes e importadores devem, ainda, enviar um laudo físico-químico de composição, segundo diretrizes do IBAMA.

\subsection{As Quantidades a serem retornadas por meio da Logística Reversa}

A meta de quantidades retornadas elaborada para o sistema de pneus prevê o retorno da totalidade de pneus fabricados, considerando que o pneu é um produto que possui um longo período de vida útil e que tem-se uma constante reposição do mercado esta é uma meta condizente com a realidade, pois como exposto anteriormente os fabricantes nos últimos relatórios demostraram ter atingido pelo menos $100 \%$ da meta proposta.

Porém, no mesmo observa-se uma discrepância entre a porcentagem da meta atingida pelos fabricantes e pelos importadores. Em consecutivos relatórios os importadores não atingiram a meta de destinação nacional, posto que talvez não haja fiscalização suficiente, dificultada pela restrição de acesso aos dados oficiais de comércio exterior, impossibilitando as operações de fiscalização ambiental, juntamente com a falta de incentivos financeiros aos fabricantes, como a redução de impostos sobre a cadeia de reciclagem, para que o preço do produto reciclado diminua os custos do produto novo.

Já o Programa ABINEE Recebe Pilhas e a Resolução do Conama oㅜ 401/08 
não impõem metas de retorno para as pilhas e baterias. Mas, ainda assim, a quantidade de produtos que alcançam um destino adequado por meio do PARP é muito menor do que a comercializada legalmente no país. Se for considerado o comércio ilegal, esse número atinge um patamar ainda maior.

As pilhas e baterias que não são compreendidas pelo PARP não apresentam um controle de destino amplamente conhecido - como as que fazem parte do programa apresentam - não sendo possível obter conclusões sobre o nível do risco apresentado ao meio ambiente com sua destinação.

Um possível gargalo para este problema pode ser o próprio consumidor, no caso de não levar as pilhas e baterias até um ponto de coleta, impossibilitando seu destino ambientalmente correto. Entretanto, se o consumidor não tem informações sobre a destinação correta dos produtos, ou incentivos para contribuir com a destinação - o que pode ser apontado como um lapso dos fabricantes, importadores e comerciantes, responsáveis por promover campanhas de educação ambiental e fornecer as referidas informações - ele pode apresentar falhas no cumprimento de suas responsabilidades.

Corroborando com esta proposição, Rocha, Rocha e Lustosa (2017, p.34) afirmam que:

A dinâmica [da Política Nacional dos Resíduos Sólidos] está conectada a cada residência fazendo sua coleta seletiva; às empresas implementando seus planos de gestão; aos gestores públicos fechando lixões e criando aterros, estabelecendo programas e projetos que sejam contínuos, e firmando parcerias com cooperativas de coletores de recicláveis. Vislumbra-se a necessidade gritante e pulsante de atividade conjunta, estratégica e direcionada.

\section{CONSIDERAÇÕES FINAIS}

A presente pesquisa relata o funcionamento de dois sistemas de logística reversa no Brasil: o de Pilhas e Baterias Portáteis, e o de Pneus Inservíveis. O estudo foi elaborado com 0 intuito de promover a comparação entre os dois sistemas, dispondo de seis tópicos de interesse, sendo estes: fluxo reverso, objetivos e metas estabelecidos, gestão dos Sistemas de Logística Reversa, número de postos de coleta, contrapartida das empresas e quantidades a serem retornadas por meio da Logística Reversa. 
A análise de tais itens permitiu a elaboração de reflexões em relação à porcentagem de material coletada, quando em comparação com a quantidade colocada em circulação; ao acesso dos consumidores ao Sistema, em especial aos pontos de coleta; à abrangência territorial dos sistemas; à fiscalização de contrabando e ainda à existência de sistemas em processo de implantação.

Durante o estudo, notou-se uma grande dificuldade em encontrar informações em livros, periódicos ou sítios eletrônicos sobre o sistema logístico pós-venda e pósconsumo de pilhas e baterias. Em contrapartida, a empresa de logística GM\&Clog disponibiliza um telefone para contato especificamente sobre o Programa ABINEE Recebe Pilhas, por meio do qual é possível encontrar profissionais capacitados para esclarecer dúvidas em relação ao Sistema.

O fato de o sistema de pilhas e baterias não ser unificado pode estar trazendo como efeito um déficit nas quantidades retornadas, ao contrário do que ocorre com o sistema de pneumáticos, visto em que os postos de coleta para pneus inservíveis se encontram em todos os revendedores de pneus novos.

Como principais desafios a serem enfrentados na implantação da logística reversa, aponta-se as divergências na legislação ambiental em diferentes áreas da União, a abrangência dos sistemas em relação ao tipo de produto, a nãopadronização na legislação referente a cada produto, e a fiscalização insuficiente sobre o contrabando de bens - gerando concorrência desleal, tendo em vista que os custos com o processo de logística reversa não têm a quem ser destinados.

Desta forma, o estudo expôs, através de critérios de comparação, informações referentes ao funcionamento dos sistemas de logística reversa dos dois itens tratados, permitindo, a partir destes critérios elencar pontos relevantes positivos e negativos de cada sistema, dando subsídios ao desenvolvimento de melhorias nos sistemas baseado nos resultados de comparação.

Como sugestões para pesquisas futuras, pode-se citar o desenvolvimento de um estudo sobre a gestão dos sistemas de logística reversa; a busca por uma solução para o completo funcionamento do Sistema de Pilhas e Baterias, empregando modelos trazidos de outros sistemas; e a elaboração de um estudo numérico envolvendo a demanda ambiental e as limitações dos sistemas, de maneira a entender o contexto de seu funcionamento e possibilitar a criação de 
metas para o futuro da Logística Reversa.

\section{REFERÊNCIAS}

ASSOCIAÇÃO BRASILEIRA DE NORMAS TÉCNICAS. ABNT NBR 10004: resíduos sólidos: classificação. Rio de Janeiro, 2004.

ABINEE. Associação Brasileira da Indústria Elétrica e Eletrônica. Relatório Anual ABINEE 2017. Publicado em: fev.2018. Disponível em:

http://www.abinee.org.br/programas/imagens/rel2017.pdf. Acesso em: 03 maio 2018.

ABINEE. Associação Brasileira dan Idústria Elétrica e Eletrônica. Panorama Econômico e Desempenho Setorial 2008, 2008. Disponível em: http://www.abinee.org.br. Acesso em: 02 abr. 2018.

ABINEE. Associação Brasileira da Indústria Elétrica e Eletrônica. Programa Abinee Recebe Pilhas: mais de 400 toneladas em quase 3 anos, 2013. Disponível em: http://www.abinee.org.br/noticias/com28.htm. Acesso em: 21 abr. 2018. ABINEE. Associação Brasileira da Indústria Elétrica e Eletrônica. Programa Abinee Recebe Pilhas: cartilha informativa. Disponível em: http://www.gmcons.com.br/gmclog/downloads/61Cartilha Programa ABINEE Recebe Pilhas.pdf. Acesso em: 11 dez. 2017.

ABINEE. Associação Brasileira da Indústria Elétrica e Eletrônica. Logística reversa de pilhas e baterias: cartilha de orientações. Mensagem recebida por: barbaratokarz@icloud.com em 30 mar. 2017 (a).

BATISTA, Leandro J. R.; MONTEIRO, Maria S. L.; SAMPAIO, Dayanne B. Gerenciamento de Pneus (In)Servíveis: Entraves e Possibilidades. Revista Espacios, vol.36 ( $\left.n^{\circ} 23\right)$ ano 2015. Disponível em: http://www.revistaespacios.com/a15v36n23/15362302.html. Acesso em: 21 abr. 2018.

BRASIL. Decreto no 7.404, de 23 de dezembro de 2010(a).

BRASIL. Lei no 12.305, de 02 de agosto de 2010. Institui a Política Nacional de Resíduos Sólidos. Brasília: Diário Oficial da União, 2010. Disponível em: https://www.planalto.gov.br/ccivil 03/ ato2007-2010/2010/lei//12305. Acesso em: 27 abr. 2018.

CONAMA. Conselho Nacional do Meio Ambiente. Resolução $n^{\circ}$ 401, de 4 de novembro de 2008. Publicado em DOU n 215, de 5 de novembro de 2008, Seção 1, página 108-109. Disponível em: http://www.mma.gov.br/port/conama/legislacao/CONAMA RES CONS 2008 401.pdf. Acesso em: 22 abr. 2018.

CONAMA. Conselho Nacional do Meio Ambiente. Resolução no 257, de 30 de junho de 1999 (a). Publicada no DOU no 139, de 22 de julho de 1999, pág 28-29. Disponível em: http://www.mma.gov.br/port/conama/legiabre.cfm?codlegi=257. Acesso em: 11 abr. 2018.

CONAMA. Conselho Nacional do Meio Ambiente. Resolução no 416, de 30 de Setembro de 2009.Publicado em DOU № 188, de 01/10/2009, págs. 64-65. Disponível em: http://www.mma.gov.br/port/conama/res/res09/res41609.pdf. Acesso em: 20 abr. 2018. 
CONAMA. Conselho Nacional do Meio Ambiente. Resolução no 258, de 26 de agosto de 1999. Publicada no DOU $n^{\circ} 230$, de 2 de dezembro de 1999, Seção 1, página 39. Disponível em: http://www.mma.gov.br/port/conama/res/res99/res25899.html. Acesso em: 16 de abr. de 2018.

DOU. Diário Oficial da União. Instrução Normativa no 8, de 3 de setembro de 2012.

FAGUNDES, Alexandre B.; TOKARZ, Barbara; PEREIRA, Delcio; BEUREN, Fernanda H.; CAMPOS, Débora B. Logística reversa de pilhas e baterias no Brasil: uma contextualização considerando o Programa ABINEE Recebe Pilhas (PARP). In: Congresso Internacional de Administração, 30., 2017, Ponta Grossa. Anais eletrônicos... Ponta Grossa: UEPG, 2017.

FLORIANI, Marco A.; FURLANETTO, Vinicius C.; SEHNEM, Simone. Descarte sustentável de pneus inservíveis. NAVUS: Revista de Gestão e Tecnologia, 2016, Vol.6(2), pp.3751 https://doi.org/10.22279/navus.2016.v6n2.p37-51.347

GIL, Antonio C. Como elaborar projetos de pesquisa. 4.ed., São Paulo: Atlas, 2002. GM\&C. Sistema de logística reversa: programa ABINEE recebe pilhas. Disponível em: http://www.gmcons.com.br/gmclog/admin/VisualizarPostosMapaCliente.aspx. Acesso em: 20 mar. 2017.

IBAMA. Instituto Brasileiro do Meio Ambiente e dos Recursos Naturais Renováveis. Relatório Pneumáticos 2017. Disponível em: http://ibama.gov.br/phocadownload/pneus/relatoriopneumaticos/ibama-relatoriopneumaticos-2017-nov.pdf. Acesso em: 16 abr. 2018

IBAMA. Instituto Brasileiro do Meio Ambiente e dos Recursos Naturais Renováveis. Relatório Pneumáticos 2016. Disponível em: http://ibama.gov.br/phocadownload/pneus/relatoriopneumaticos/ibama-relatoriopneumaticos-2016.pdf. Acesso em 07 de abr. de 2018.

IBAMA. Instituto Brasileiro do Meio Ambiente e dos Recursos Naturais Renováveis. Instrução Normativa n`1, de outubro de 2009. Disponível em: http://ibama.gov.br/phocadownload/consultapublica/antigos/ibamaminuta instruo normativa pneus.pdf. Acesso em: 22 abr. 2018'

LAKATOS, E. M.; MARCONI, M. A. Técnicas de Pesquisa. 6.ed., São Paulo: Atlas, 2006. LEITE, Paulo R. Logística reversa: nova área da logística empresarial (1 $1^{a}$ parte). Revista Tecnologística, São Paulo, maio 2002. Disponível em: http://meusite.mackenzie.br/leitepr/LOG\%CDSTICA\%20REVERSA\%20\%20NOVA\%20\%C1REA\%20DA\%20LOG\%CDSTICA\%20EMPRESARIAL.pdf. Acesso em: 27 abr. 2018.

LYRIO, Carina S.; CHAVES, Gisele L. D. A legislação efetivamente envolveu os consumidores no descarte adequado de pilhas e baterias. Revista Eletrônica em Gestão, Educação e Tecnologia Ambiental, v. 19, n. 3, p. 222-238, 2015.

MENDES, Henrique M. R.; RUIZ, Mauro S.; FARIA, Ana C. Programa ABINEE recebe pilhas (PARP): A implantação e estágio atual da logística reversa de pilhas e baterias. Encontro Nacional Sobre Gestão Empresarial e Meio Ambiente. São Paulo, 2015.

MENEZES, E. M.; SILVA, E. L. Metodologia da Pesquisa e Elaboração de Dissertação. 4.ed., rev. Atual, Florianópolis: laboratório de ensino a distância da UFSC, 2005. 
MMA. Ministério do Meio Ambiente. Gestão de Resíduos: a problemática "resíduos sólidos". Disponível em: http://www.mma.gov.br/responsabilidade-socioambiental/a3p/eixostematicos/gest\%C3\%A3o-adequada-dos-res\%C3\%ADduos. Acesso em: 16 abr. 2018.

RECICLANIP. Elementos sobre a destinação ambientalmente adequada de pneumáticos inservíveis. 2008. Disponível em:

http://www.mma.gov.br/port/conama/processos/83C56F5F/PropANIP ElementosDestPneus. pdf. Acesso em: 21 abr. 2018.

RECICLANIP. Entidades Internacionais. Disponível em:

http://www.reciclanip.org.br/v3/entidades-internacionais. Acesso em: 21 Abr. 2018(c).

RECICLANIP. Estratégias. Disponível em: http://www.reciclanip.org.br/v3/quem-somosestrategias. Acesso em: 21 Abr. 2018(b).

RECICLANIP. Industria já recolheu mais de 4 milhões de toneladas de pneus inservíveis. Disponível em: http://www.reciclanip.org.br/v3/releases/industria-ja-recolheumais-de-4-milhoes-de-toneladas-de-pneus-inserviveis/88/20161129/. Acesso em: 27 abr. 2018(f).

RECICLANIP. Institucional. Disponível em: http://www.reciclanip.org.br/v3/quem-somosinstitucional. Acesso em: 21 abr. 2018.

RECICLANIP. O que são pontos de coleta de pneus. Disponível em: http://www.reciclanip.org.br/v3/pontos-de-coleta-o-que-sao. Acesso em: 21 abr. 2018(d).

RECICLANIP. Para onde vão os pneus inservíveis. Disponível em: http://www.reciclanip.org.br/v3/formas-de-destinacao-para-onde-vao. Acesso em: 21 abr. 2018(a).

ROCHA, Suyene Monteiro da; ROCHA, Renata Rodrigues de Castro; LUSTOSA, Kárita Barros. Política brasileira de resíduos sólidos: reflexões sbore a geração de resíduos e sua gestão no município de Palmas -TO. Revista ESMAT, [S.I.], v. 9, n. 13, p. 29-44, dez. 2017. Disponível em: http://esmat.tito.jus.br/publicacoes/index.php/revista esmat/article/view/189. Acesso em: 17 abr. 2018.' https://doi.org/10.34060/reesmat.v9i13.189

SEMA. Secretaria de Estado do Meio Ambiente e Recursos Hídricos. Termo de Compromisso para responsabilidade pós-consumo de pilhas e baterias portáteis. Termo assinado em 04 de agosto de 2017. Disponível em: http://www.meioambiente.pr.gov.br/arquivos/File/TC ABINNE 2017.pdf. Acesso em: 12 abr. 2018.

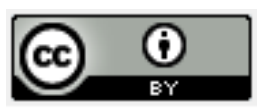

Artigo recebido em: 05/05/2018 e aceito para publicação em: 04/03/2020 DOI: http://dx.doi.org/10.14488/1676-1901.v20i1.3241 